\title{
Identification of phase relative genes in tetrasporophytes and female gametophytes of Gracilaria/Gracilariopsis lemaneiformis (Gracilariales, Rhodophyta)
}

\author{
Xueying Ren \\ College of Marine Life Sciences \\ Ocean University of China \\ Qingdao, 266003, P. R. China \\ Tel: 08653282032789 \\ E-mail: rxyren2004409@yahoo.com.cn \\ Xuecheng Zhang* \\ College of Marine Life Sciences \\ Ocean University of China \\ Qingdao, 266003, P. R. China \\ Tel: 08653282032789 \\ E-mail: xczhang@ouc.edu.cn \\ Zhenghong Sui \\ College of Marine Life Sciences \\ Ocean University of China \\ Qingdao, 266003, P. R. China \\ Tel: 08653282032789 \\ E-mail: suizhengh@ouc.edu.cn
}

Financial support: National Scientific Foundation of China (No. 30170736) and National "863" High-tech Program of China (No. 2004AA603220).

Keywords: female gametophyte, Gracilaria/Gracilariopsis lemaneiformis, suppression subtractive hybridization, tetrasporophyte, Virtual Northern blot.

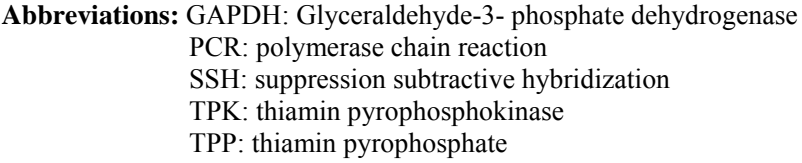

Genes differentially expressed between tetrasporophytes and female gametophytes of Gracilaria/Gracilariopsis lemaneiformis were isolated by suppression subtractive hybridization (SSH) and screened by dot-blot macroarrays. Different expression profiles of selected clones based on the results of dot-blot macro-arrays were verified using virtual Northern blots. Totally, 14 phase relative cDNAs had been isolated and sequence identified. Among them, seven cDNAs were respectively homologous to crucial metabolic enzymes, Rab GTPase, RP42 homolog, and two hypothetical proteins, while the rest did not have significant hits in the databases examined. The results of virtual Northern blots revealed that 11 cDNAs were differentially expressed between the two samples, including 7 genes up-regulated in tetrasporophytes, 1 expressed exclusively in tetrasporophytes and 3 up-regulated in female gametophytes. By densitometric analysis relative to GAPDH, 8 cDNAs increased 1.3-4.2 fold and 3 decreased about 0.4-0.7 fold in tetrasporophytes compared to female gametophytes. The present study provides the first insight into genes that may involve in phase differentiation in G. lemaneiformis.

Gracilaria/Gracilariopsis lemaneiformis, an economically important agarophyte, has been under cultivation on a large scale in China and has been appreciated as a food and feed for culturing marine animals and formerly as a binding matural in the preparation of lime for painting walls. The most important use of Gracilaria, however, is the production of agar (Tseng, 2001). Besides its economic importance, G. lemaneiformis is also an ideal material for a variety of genetical studies owning the following traits (Zhang et al. 2004). Firstly, it can complete its life cycle under laboratory conditions. Secondly, pigmentation and morphological mutants are easy to be generated by physical or chemical mutagenesis. Thirdly, tetraspores and carpospores can be obtained at anytime under proper culture conditions.

The species possesses three isomorphic life-history phases,

* Corresponding author 
gametophyte, carposporophyte and tetrasporophyte. Phase differentiation is associated with numerous important physiological changes and many genes are developmentally regulated and expressed in a phase relative manner. Since 1976, investigations have been conducted on differential detection of proteins to find phase relative genes in algae (Hoxmark, 1976; Hushovd et al. 1982). Due to the drawbacks of applicable methods at that time, there were no satisfactory results. With the development of molecular biology, large-scale gene expression studies have been undertaken to understand the molecular mechanisms of phase differentiation in algae. Liu et al. (1994) employed cDNA subtracted hybridization to study phase-specific genes in Porphyra purpurea and fifteen genes were identified. Although they have demonstrated the power of subtracted cDNA libraries, it is very complicated, timeconsuming and subjected to lose genes expressed at low levels. Sun et al. (2002) reported an analysis of a total of 180 ESTs generated from a cDNA library from gametophytic G. lemaneiformis. Sequence analysis revealed that the majority of the ESTs were involved in photosynthesis, DNA transcription or translation, and few clones were associated with growth or development, signal transduction and stress or defence responses. Despite these advances, the molecular mechanisms of phase differentiation in algae are still poorly understood and many phase relative genes remain to be discovered. Under this background, suppression subtractive hybridization ( $\mathrm{SSH}$ ) was performed between RNA isolated from tetrasporophytes and female gametophytes of $G$. lemaneiformis to obtain more comprehensive knowledge of the molecular events involved in phase differentiation in Gracilaria. SSH was developed by Diatchenko et al. (1996) and turned out to be a successful tool for rapid screening of differentially expressed genes (Wei et al. 2001; Caturla et al. 2002; Lee et al. 2002; Osherov et al. 2002; Cramer and Lawrence, 2004). In plants, there are increasing applications of the method in identifying genes differentially expressed during developmental processes, such as bud formation, gametophore formation and flower maturation, etc. (Brun et al. 2003; Ok et al. 2003; Shary and Guha-Mukherjee, 2004). The findings in this report enhance our understandings of the phase differentiation process in Gracilaria.

\section{MATERIALS AND METHODS}

\section{Algae collection and cultivation}

G. lemaneiformis, collected from Zhanshan Bay (Qingdao, China), thoroughly rinsing and culturing in sterilized sea water, under the light intensity of $50 \mu \mathrm{mol}$ photon $/ \mathrm{m}^{2} / \mathrm{s}$ with a 12:12 (L:D) cycle at $15 \pm 11^{\circ} \mathrm{C}$. Tetrasporophytes and female gametophytes were distinguished by the existing of tetraspores and carpospores, respectively. The immature tips of the thalluses were used for RNA extraction.

\section{RNA isolation and cDNA synthesis}

Total RNA was isolated from each sample with Trizol reagent (Sangon, China), reverse-transcribed and amplified using a SMART PCR cDNA synthesis kit (BD Biosciences Clontech, USA) according to the manufacturer's instructions.

\section{Suppression subtractive hybridization}

A two-directional (forward and backward) SSH was performed using a PCR-select cDNA subtraction kit (BD Biosciences Clontech, USA). The cDNA generated from the SMART protocol was digested with RsaI, purified using a TaKaRa agarose gel purification kit (TaKaRa, Japan) and ligated to adapters (included in the SSH kit). The subtractive hybridization products were then amplified by suppression PCR. The products of the second PCR were purified and inserted into T/A cloning vector (Promega, USA).

Table 1. Putative phase relative genes identified from the SSH libraries of G. lemaneiformis.

\begin{tabular}{|c|c|c|c|c|c|}
\hline Clone & GenBank accession no. & Insert size & Putative function $^{\mathrm{a}}$ & E-value & Identity \\
\hline $\mathrm{SSH} 4$ & DQ008074 & 481 & Rab GTPase & $2 e-64$ & $122 / 152(80 \%)$ \\
\hline SSH5 & DQ008075 & 373 & No match & & \\
\hline SSH302 & DQ008076 & 372 & Thiamin pyrophosphokinase & $1 e-14$ & 42/115 (36\%) \\
\hline SSH391 & DQ008087 & 326 & No match & & \\
\hline SSH407 & DQ008077 & 390 & GMP synthase & $1 e-28$ & $58 / 82(70 \%)$ \\
\hline SSH415 & DQ008078 & 328 & No match & & \\
\hline SSH424 & DQ008079 & 505 & RP42 homolog & $1 e-14$ & $42 / 102(41 \%)$ \\
\hline SSH425 & DQ008080 & 284 & No match & & \\
\hline SSH427 & DQ008081 & 245 & No match & & \\
\hline SSH436 & DQ008082 & 257 & hypothetical protein & $8 e-28$ & $55 / 83(66 \%)$ \\
\hline SSH454 & DQ008083 & 712 & No match & & \\
\hline SSH466 & DQ008084 & 302 & No match & & \\
\hline SSH486 & DQ008085 & 462 & hypothetical protein & $4 e-07$ & $31 / 63(49 \%)$ \\
\hline SSH528 & DQ008086 & 315 & aspartate aminotransferase & $1 e-21$ & $53 / 105(50 \%)$ \\
\hline
\end{tabular}

${ }^{a}$ Putative functions were designated based on BLASTx searches of the public database. Only E-values $<10$ - 3 were considered significant and reported in this table. 


\section{Dot-blot differential screening of cDNA clones}

In order to confirm differential expressions of the clones, cDNA dot-blots were performed according to the manufacturer's protocol in the PCR-select differential screening kit (BD Biosciences Clontech, USA). Nested primers 1 and 2R (included in the SSH kit) were used to PCR amplify 384 white colonies randomly selected from each of the two subtracted libraries. Thermal cycling was conducted under the following conditions, $94^{\circ} \mathrm{C}$ for $30 \mathrm{~s}$, then 30 cycles of $94^{\circ} \mathrm{C}$ for $10 \mathrm{~s}, 68^{\circ} \mathrm{C}$ for $3 \mathrm{~min}$. PCR products were dot-blotted onto nylon membranes in duplicate (Amersham Pharmacia Biotech, CK). Both forward and backward subtracted cDNAs were treated by RsaI restriction enzyme to remove adaptors, labeled with ${ }^{32} \mathrm{p}$ using the random primer labelling of cDNA protocol in the PCR-select differential screening kit and used as probes. Membranes were hybridized with probes at $70^{\circ} \mathrm{C}$ overnight. After hybridization, membranes were washed once in $2 \times \mathrm{SSC}, 0.1 \%$ SDS and twice in $0.2 \times \mathrm{SSC}, 0.1 \%$ SDS for $15 \mathrm{~min}$, then exposed to X-ray film for 3 days.

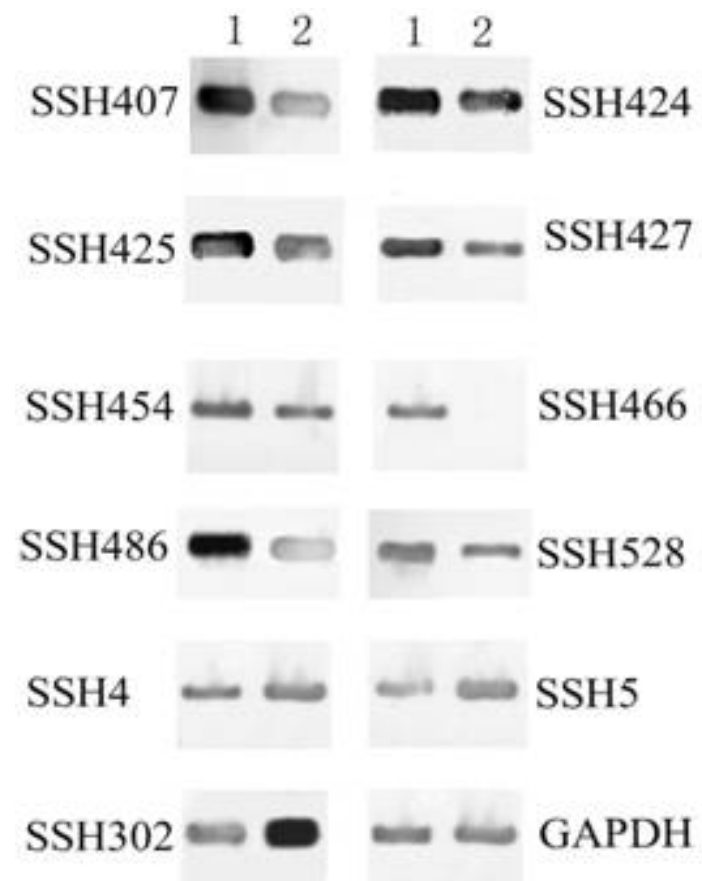

Figure1. Representative Virtual Northern blots to detect the expression patterns of the SSH cDNAs. GAPDH was used as an internal control to insure the un-contamination of cDNAs.

1: The cDNA population of tetrasporophytes;

2: The cDNA population of female gametophytes.

The hybridization results of SSH391, SSH415 and SSH436 were not shown.

\section{DNA sequencing and analysis}

Plasmid DNAs selected from SSH were purified using Qiagen plasmid miniprep kit (Qiagen, German). DNA sequencing was performed with an $\mathrm{ABI} 3770$ automatic sequencer (ABI Prism, Perkin-Elmer) and sequences were analyzed using the BLAST algorithms at the National Center for Biotechnology Information (NCBI).

\section{Virtual Northern blot and densitometric analysis}

Virtual Northern blots were carried out using a Dig high prime DNA labelling and detection starter kitI (Roche Molecular Biochemicals, Germany) according to the manufacturer's directions. Double stranded cDNAs were generated using a SMART PCR cDNA synthesis kit (BD Biosciences Clontech, USA). In each blot, $1 \mu \mathrm{g}$ of doublestranded cDNA from each sample was electrophoresed in a $1 \%$ agarose gel, processed (denatured and neutralized), and transferred to a nitrocellulose membrane. Selected individual cDNA clones generated from the subtractive procedure were used as probes. The control GAPDH probe was generated from $80 \mathrm{ng}$ of $\mathrm{G}$. lemaneiformis genomic DNA using the primers 5'AAGTATGACTCCACGCACGG3' and 5' CTCCTCTCCAATCCTTGTGCGACGGGC3'. All virtual Northern blots were repeated three times. The intensity of the hybridization signals was quantified by computer densitometry and normalized to the expression level of the GAPDH gene. All data were expressed as means \pm SEM. Data comparisons were made by Student's $t$ tests, with statistical significance taken at $\mathrm{P}<0.05$.

\section{RESULTS}

Screening of the forward and backward subtracted cDNA libraries by macro-array dot-blots

In the case of cDNA dot blot analysis, PCR amplified inserts (using nested primers 1 and 2R) representing 768 white clones were arrayed on 8 nylon membranes, in duplicate. Both forward (female gametophytes minus tetrasporophytes) and backwardsubtracted (tetrasporophytes minus female gametophytes) radioactively labelled cDNA populations were then used as individual probes for identical blots. Of the 768 colonies examined, 14 were up-regulated or down-regulated in tetrasporophytes compared to female gametophytes. These 14 clones were sequenced and selected for further qualitative and quantitative hybridizations.

\section{Analysis of the SSH cDNA clones}

Fourteen sequenced clones, with an average insert size of $383 \mathrm{bp}$, ranging from 245 to $712 \mathrm{bp}$, were deposited in GenBank under accession numbers DQ008074- DQ008087 and used to search the GenBank non-redundant database (Table 1). Clone SSH4 had high homology with genes encoding Rab GTPases, clone SSH424 had homology with a RP42 gene, three clones (SSH302, SSH407, SSH528) were respectively homologous to thiamin pyrophosphokinase, GMP synthase and aspartate aminotransferase, which were all metabolism involved genes, two clones (SSH436, SSH486) were homologous to 
genes for hypothetical proteins, and the rest seven had no significant hits in the database.

\section{Expression of the SSH cDNA clones}

Fourteen clones, based on the results from the dot-blot screens, were selected for virtual Northern blot analysis to further confirm their differential expressions. Glyceraldehyde-3- phosphate dehydrogenase (GAPDH) gene was used as a control, which exhibited a constitutive expression, thus validating the performance of the protocol. The results revealed that $78 \%(11 / 14)$ clones were differentially expressed between the two samples. Figure 1 presents the virtual Northern blot results for 11 selected clones. SSH4, SSH5 and SSH302 were up-regulated in female gametophytes, and seven cDNAs (SSH407, SSH424, SSH425, SSH427, SSH486 SSH454 and SSH528) were up-regulated in tetrasporophytes. SSH391 did not give any hybridization signals, whose expression level might be below the detection limit. SSH415 and SSH436 were expressed at the same level between the two phases (not shown in Figure 1). SSH466 was expressed exclusively in tetrasporophytes. The results of densitometric analysis after normalization against hybridization signals for GAPDH revealed that the mean relative densities of these clones ranged from 0.4 to 4.2 fold in tetrasporophytes compared to female gametophytes (Table 2).

\section{DISCUSSION}

For the first time, we report the differentially expressed genes which may involve in phase development in $G$. lemaneiformis. Of the 14 cDNAs identified, clone SSH4 had high homology with other reported Rab GTPases, especially from animals. Rab GTPases, one of the biggest subfamilies of small GTPases, act as essential regulators of vesicular transport pathways (Lazar et al. 1997; Novick and Zerial, 1997; Pereira-Leal and Seabra, 2000) and involve in the regulation of diverse cellular functions including growth and differentiation, etc. (Hall, 1990; Schimmöller et al. 1998; Matozaki et al. 2000; Corbett and Alber, 2001).
The expression of SSH4 was a little bit higher $(0.3$ fold, $\mathrm{p}<$ $0.05)$ in female gametophytes compared to tetrasporophytes. This increase might enhance vesiclemediated transports. It was observed that the expression of Rab5a was up-regulated during root development in rice Oryza sative L., maybe because endocytosis was responsible for the uptake of essential nutrients from the external environment (Wang et al. 2002). However, further proofs such as sub cellular localization of Rab will be essential to elucidate its specific role during phase differentiation in G. lemaneiformis. Clone SSH 302 was homologous to thiamin pyrophosphokinase (TPK) (EC 2.7.6.2). TPK catalyzes the pyrophosphorylation of thiamin with adenosine 5'-triphosphate to form thiamin pyrophosphate (TPP). TPP is a necessary compound associated with glycolysis and tricarboxylic acid cycle. Thus, the differential expression of the TPK gene during phase differentiation in $G$. lemaneiformis could cause energy difference between the two phases.

Clone SSH407 had homology to GMP synthase. By densitometric analysis of blots normalized to GAPDH, the expression of SSH407 increased nearly 3 fold in tetrasporophytes as compared to female gametophytes. It was reported that the expression of GMP synthase gene was increased with the levels of DNA and RNA synthesis at the points in the life cycle (McConkey, 2000). Clone SSH424 was homologous to RP42 which was developmentally regulated and may be involved in proliferative functions (Mas et al. 2000). Clone SSH528 was homologous to aspartate aminotransferase which was reported to be correlated with the content of certain amino acids, such as the content of cysteine, asparagine, glutamine and aspartic acid (O'Farrell et al. 1997). As a result of the differential expressions of the above metabolism involved genes, the amount of some nucleic acids and amino acids synthesized may be different between the two developmental stages. Consequently, the levels of metabolism are probably different between them. This is consistent with the fact that they are different in some physiological characters such as growth rate, etc. (Kain and Destombe, 1995; Zhang and

Table 2. Densitometric analysis of the hybridization signals in Figure 1 (Mean $\pm S E M, n=3$ each).

\begin{tabular}{|c|c|c|c|}
\hline Clone & Mean density in $\mathbf{F}^{\mathbf{a}}$ & Mean density in $\mathbf{T}^{\mathbf{b}}$ & Relative intensity $^{\mathbf{c}}$ \\
\hline SSH407 & $0.77 \pm 0.08$ & $2.32 \pm 0.23^{*}$ & 3.0 \\
\hline SSH424 & $1.51 \pm 0.15$ & $2.22 \pm 0.02^{*}$ & 1.5 \\
\hline SSH425 & $1.15 \pm 0.13$ & $2.15 \pm 0.21^{*}$ & 1.9 \\
\hline SSH427 & $0.89 \pm 0.27$ & $1.65 \pm 0.24^{*}$ & 1.9 \\
\hline SSH454 & $0.98 \pm 0.05$ & $1.39 \pm 0.16$ & 1.4 \\
\hline SSH466 & 0 & $0.96 \pm 0.11$ & 4.2 \\
\hline SSH486 & $0.51 \pm 0.12$ & $2.14 \pm 0.13^{*}$ & 1.3 \\
\hline SSH528 & $0.93 \pm 0.04$ & $1.20 \pm 0.11^{*}$ & 0.7 \\
\hline SSH4 & $1.14 \pm 0.23$ & $0.83 \pm 0.21^{*}$ & 0.6 \\
\hline SSH5 & $0.91 \pm 0.19$ & $0.58 \pm 0.17$ & 0.4 \\
\hline SSH302 & $2.14 \pm 0.07$ & $0.94 \pm 0.09$ & \\
\hline
\end{tabular}

\footnotetext{
${ }^{a}$ Mean density in female gametophytes normalized to GAPDH.

${ }^{b}$ Mean density in tetrasporophytes normalized to GAPDH.

${ }^{\mathrm{c}}$ The relative intensity in tetrasporophytes compared to female gametophytes.

* $\mathrm{p}<0.05$
} 
Van der Meer, 1988). Therefore, the genes identified in this study may be utilized as novel molecular markers in future genetic breeding of $G$. lemaneiformis.

Among the genes of unknown functions, SSH391 did not hybridize with either of the samples, maybe because its expression level was too low to be detected. SSH415 and SSH436 are false positive, expressed at the same level between the two samples. Of particular interest is SSH466 which appears to be expressed solely in tetrasporophytes and is likely to be a tetrasporophyte-specific gene. SSH466 showed significantly differential expression and increased 4. 2 fold in tetrasporophytes compared to female gametophytes. It will be of great interest to study the specific role of SSH466 during phase differentiation in Gracilaria. Future studies will be focused on cloning the full-length cDNA sequences of these genes and using in situ hybridization and gene disruption techniques, etc. to elucidate their functions. The identification and characterization of all these differentially expressed genes will provide important clues to the probable metabolic pathways and/or structural features unique to the maturation of red algae.

\section{ACKNOWLEDGMENTS}

Authors would like to thank Shu Wei Wang for his technical assistance and Aruna Kumara for his critical readings of the manuscript.

\section{REFERENCES}

BRUN, Florent; GONNEAU, Martine; LALOUE, Michel and NOGUE, Fabien. Identification of Physcomitrella patens genes specific of bud and gametophore formation. Plant Science, December 2003, vol. 165, no. 6, p. 12671274.

CATURLA, Mercé; CHAPARRO, Cristian; SCHROEYERS, Katrien and HOLSTERS, Marcelle. Suppression subtractive hybridization to enrich lowabundance and submergence-enhanced transcripts of adventitious root primordia of Sesbania rostrata. Plant Science, June 2002, vol. 162, no. 6, p. 915-921.

CORBETT, Kevin D. and ALBER, Tom. The many faces of Ras: recognition of small GTP-binding proteins. Trends in Biochemical Sciences, December 2001, vol. 26, no. 12, p. $710-716$.

CRAMER, Robert A. and LAWRENCE, Christopher B. Identification of Alternaria brassicicolagenes expressed in planta during pathogenesis of Arabidopsis thaliana. Fungal Genetics and Biology, February 2004, vol. 41, no. 2, p. 115-128.

DIATCHENKO, Luda; LAU, Yun-Fai Chris; CAMPBELL, Aaron P.; CHENCHIK, Alex; MOQADAM, Fauzia; HUANG, Betty; LUKYANOV, Sergey; LUKYANOV,
Konstantin; GURSKAYA, Nadya; SVERDLOV, Eugene D. and SIEBERT, Paul D. Suppression subtractive hybridization: a method for generating differentially regulated or tissue specific cDNA probes and libraries. Proceedings of the National Academy of Sciences of the United States of America, June 1996, vol. 93, no. 12, p. 6025-6030.

HALL, A. The cellular functions of small GTP-binding proteins. Science, August 1990, vol. 249, no. 4969, p. 635640.

HOXMARK, R.C. Protein composition of different stages in the life cycle of Ulva mutabilis, Foeyn. Planta, 1976, vol. 130 , no. 3, p. 327-332.

HUSHOVD, O.T.; GULLIKSEN, O.M. and NORDBY, O. Absence of major differences between soluble proteins from haploid gametophytes and diploid sporophytes in the green algae Ulva mutabilis Foeyn. Planta, 1982, vol. 156, no. 1, p. $89-91$.

KAIN, J.M. and DESTOMBE, C. A review of life history, reproduction and phenology of Gracilaria. Journal of Applied Phycology, 1995, vol. 7, no. 3, p. 269-281.

LAZAR, Thomas; GOTTE, Martin and GALLWITZ, Dieter. Vesicular transport: how many Ypt/Rab-GTPases make a eukaryotic cell? Trends in Biochemical Sciences, December 1997, vol. 22, no. 12, p. 468-472.

LEE, Kai-Fai; YAO, Yuan-Qing; KWOK, Ka-Leung; XU, Jia-Sen and YEUNG, William S.B. Early developing embryos affect the gene expression patterns in the mouse oviduct. Biochemical and Biophysical Research Communications, March 2002, vol. 292, no. 2, p. 564-570.

LIU, Qing Yan; VAN DER MEER, John P. and REITH, Michael E. Isolation and characterization of phase specific complementary DNAs from sporophytes and gametophytes of Porphyra purpurea (Rhodophyta) using subtracted complementary DNA libraries. Journal of Phycology, June 1994, vol. 30, no. 3, p. 513-520.

MAS, Christophe; BOURGEOIS, Francine; BULFONE, Alessandro; LEVACHER, Béatrice; MUGNIER, Claude and SIMONNEAU, Michel. Cloning and expression analysis of a novel gene, RP42, mapping to an Autism susceptibility locus on 6q16. Genomics, April 2000, vol. 65 , no. 1 , p. $70-74$.

MATOZAKI, Takashi; NAKANISHI, Hiroyuki and TAKAI, Yoshimi. Small G-protein networks: their crosstalk and signal cascades. Cellular Signalling, August 2000 , vol. 12 , no. 8, p. 515-524.

MCCONKEY, Glenn A. Plasmodium falciparum:Isolation and characterisation of a gene encoding Protozoan GMP synthase. Experimental Parasitology, January 2000, vol. 
94 , no. 1 , p. 23-32.

NOVICK, Peter and ZERIAL, Marino. The diversity of RAB proteins in vesicle transport. Current Opinion in Cell Biology, August 1997, vol. 9, no. 4, p. 496-504.

O'FARRELL, Paul A. ; SANNIA, Giovanni; WALKER, John M. and DOONAN, Shawn. Cloning and Sequencing of Aspartate Aminotransferase from Thermus aquaticus YT1. Biochemical and Biophysical Research Communications, October 1997, vol. 239, no. 3, p. 810815.

OK, Sung Han; PARK, Hyun Mi; KIM, Ji Young; BAHN, Sung Chul; BAE, Jung Myung; SUH, Mi Chung; Jeung, JiUng; KIM, Kyung-Nam and SHIN, Jeong Sheop. Identification of differentially expressed genes during flower development in carnation (Dianthus caryophyllus). Plant Science, August 2003, vol. 165, no. 2, p. 291-297.

OSHEROV, Nir; MATHEW, John; ROMANS, Angela and MAY, Gregory S. Identification of conidial-enriched transcripts in Aspergillus nidulans using suppression subtractive hybridization. Fungal Genetics and Biology, November 2002, vol. 37, no. 2, p. 197-204.

PEREIRA-LEAL, José B. and SEABRA, Miguel C. The mammalian Rab family of small GTPases: definition of family and subfamily sequence motifs suggests a mechanism for functional specificity in the Ras superfamily. Journal of Molecular Biology, August 2000, vol. 301 , no. 4 , p. 1077-1087.

SCHIMMÖLLER, Frauke; SIMON, Iris and PFEFFER, Suzanne R. Rab GTPases, directors of vesicle docking. The Journal of Biological Chemistry, August 1998, vol. 273, no. 35 , p. 22161-22164.

SHARY, Semarjit and GUHA-MUKHERJEE, Sipra. Isolation and expression studies of differentiation-specific genes in tobacco dihaploids using PCR-based subtractive hybridization method. Plant Science, February 2004, vol. 166 , no. 2, p. 317-322.

SUN, X.; YANG, G.P.; MAO, Y.X.; ZHANG, X.C. and SUI, Z.H. Analysis of expressed sequence tags of a marine red alga, Gracilaria lemaneiformis. Progress in Natural Science, July 2002, vol. 12, no. 7, p. 518-523.

TSENG, C. K. Algal biotechnology industries and research activities in China. Journal of Applied Phycology, August 2001, vol. 13, no. 4, p. 375-380.

WANG, Xiaobing B.; XIA, Ming; CHEN, Qingshuang S.; WU, Zhongchang C. and WU, Ping. Identification of a new small GTP-binding protein gene OsRab5a, genomic organization, and expression pattern analysis during nitrate supply and early nutrient starvation in rice (Oryza sativa L.) root. Plant Science, August 2002, vol. 163, no. 2, p. 273-
280.

WEI, Huijun; SCHERER, Mario; SINGH, Archana; LIESE, Ralf and FISCHER, Reinhard. Aspergillus nidulans $\alpha-1,3$ Glucanase (Mutanase), mutA, is expressed during sexual development and mobilizes mutan. Fungal Genetics and Biology, December 2001, vol. 34, no. 3, p. 217-227.

ZHANG, X.C. and VAN DER MEER, J.P. A genetic study on Gracilaria sjoestedtii. Canadian Journal of Botany, 1988, vol. 66, no. 10. p. 2022-2026.

ZHANG, X.C.; Qing, S.; MA, J.H. and XU, P. The Genetics of Marine Algae. Beijing, Agricultural Press of China, 2004, 335 p. ISBN 7-109-09525-8. 